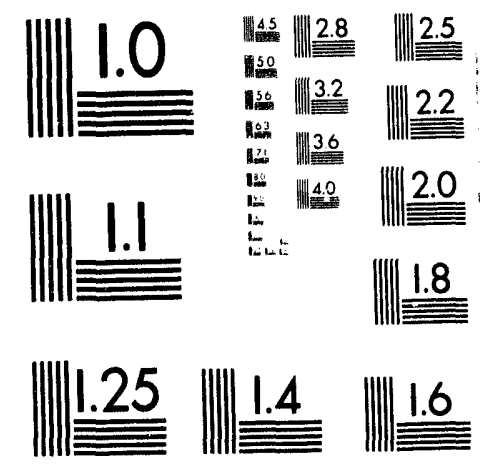



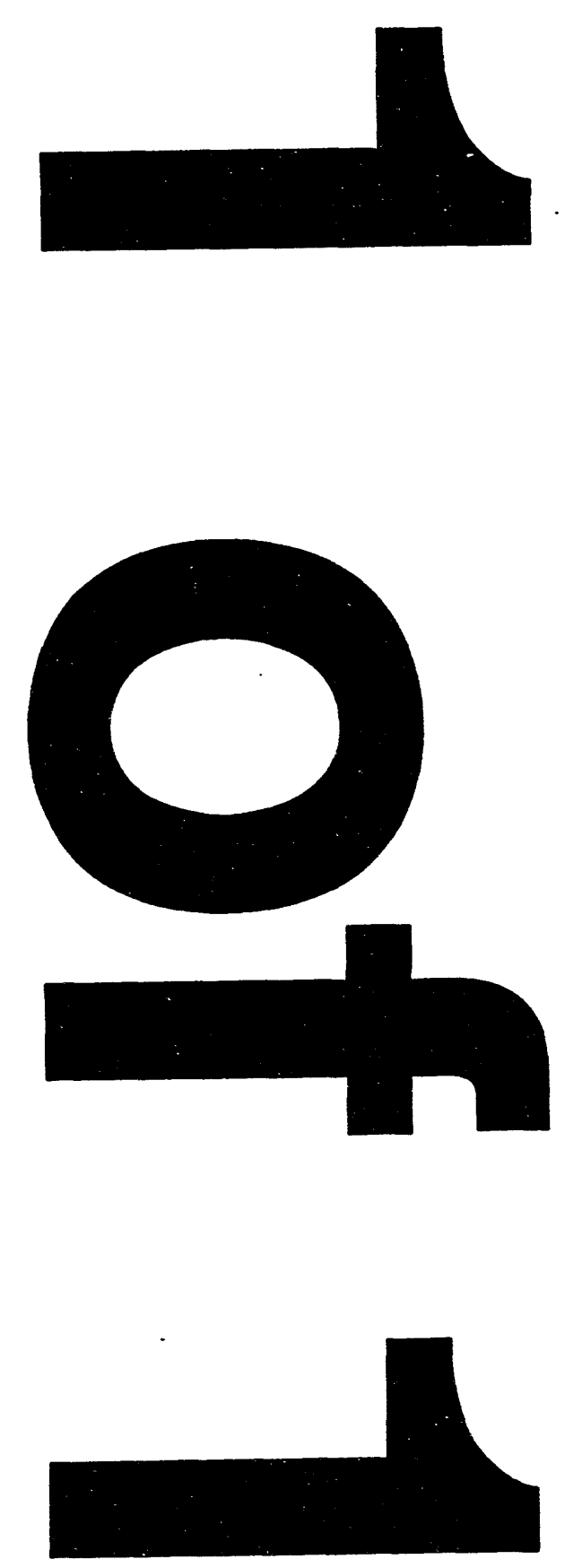
SAND93-8221

Unlimited Release

Printed January 1994

\title{
TEARING RESISTANCE OF A THIN SHELL AGAINST PROJECTILE PENETRATION -- MATERIAL PROPERTY EFFECTS
}

\author{
K. V. Trinh \\ Structural Mechanics Department \\ Sandia National Laboratories/California
}

\begin{abstract}
This report presents results from a series of finite element analyses performed to study material effects on the tearing resistance of a thin shell subjected to projectile penetration. These analyses simulated a round, slender projectile impacting the top center of a metallic cylindrical shell at high speed. We varied eight selected shell material properties systematically using an L18 matrix (design of experiment technique). From the results, we determined effects of the eight properties on the minimum projectile velocity required to penetrate the shell. The material properties examined here included: yield strength, hardening and recovery characteristics, heat coefficient, initial porosity, and damage exponent (a void growth parameter). The DYNA2D finite element code along with the Sandia plasticity/damage model for ductile metals were used in the analyses.
\end{abstract}




\section{Acknowledgement}

The author gratefully acknowledges the contribution of D. A. Krein, who performed a large portion of the computational work in this report during his Summer internship at Sandia, California. 


\section{Introduction}

This paper presents results from a series of finite element analyses performed to study effects of material properties on the resistance of thin shells against projectile penetration. Results obtained here can be used to design more penetration resistant components.

The series of analyses simulated a long, slender rod impacting the top center of a thin cylindrical shell. The rod represented a high velocity projectile such as a bullet. We used the DYNA2D finite element code (Ref. 1) and the Sandia plasticity/damage model for ductile metals (Ref. 2) to simulate the impact and to predict tearing in the shell's wall. We used one finite element mesh, but changed the shell's material properties throughout the series. From the finite element results, we calculated material property effects on the minimum projectile velocity required to penetrate the shell.

For effectiveness, we used the design of experiment technique to develop an analysis matrix. An L18 matrix (Ref. 3) was selected to investigate the main effects of eight shell's material properties. We assumed interactions between the selected properties were negligible.

It is important that readers be familiar with the Sandia plasticity/damage model since the selected material properties are used in the model. This study was a hypothetical material study; material properties defined as "trial materials" in the L18 matrix were selected regardless of whether these trial materials can be produced. We did not conduct any verification experiment because of this hypothetical nature. This analysis series can also be viewed as a penetration sensitivity study of the Sandia damage model. A short description of the model is included in Appendix A.

Besides projectile penetration, many other extreme mechanical loads are possible in an abnormal environment. The work summarized in this report is a part of the Advanced Barrier Project, an ongoing effort to study material and geometry effects on tearing resistance of thin shell structures under various mechanical loads.

Component housing designers can use the knowledge obtained from this project to make trade-off decisions in optimizing their designs. Safety assessors can apply this knowledge in assessing the response of existing and future components to extreme mechanical loads.

In the following sections, we first describe the geometry, the material properties, the analysis matrix, and the finite element modeling method. We then present the results, a discussion, and conclusions. 


\section{Analyses}

\subsection{Geometry}

Figure 1 shows the geometry selected for all analyses in this study. This simple geometry allowed for 2D modeling. The shell was cylindrical. It had an 8.0 in diameter and a 0.0625 in wall thickness. The shell edge was fixed. The penetrator was 4.0 in long and had a 1.0 in diameter. The penetrator's smooth ends had a 0.0625 in edge radius.

\subsection{Material}

The penetrator represented a high strength steel projectile. We modeled it as an elastic material with a $30 . * 10^{6}$ psi Young's modulus and a Poisson's ratio of 0.3 . Penetrator deformation was assumed to be negligible.

The Sandia plasticity/damage model was used for the shell material's constitutive model. Eight material properties were varied throughout the analysis matrix. We kept all other material properties required by the Sandia model constant (see Appendix A). Table 1 lists these constant material values. These values came from existing data for $304 \mathrm{~L}$ stainless steel.

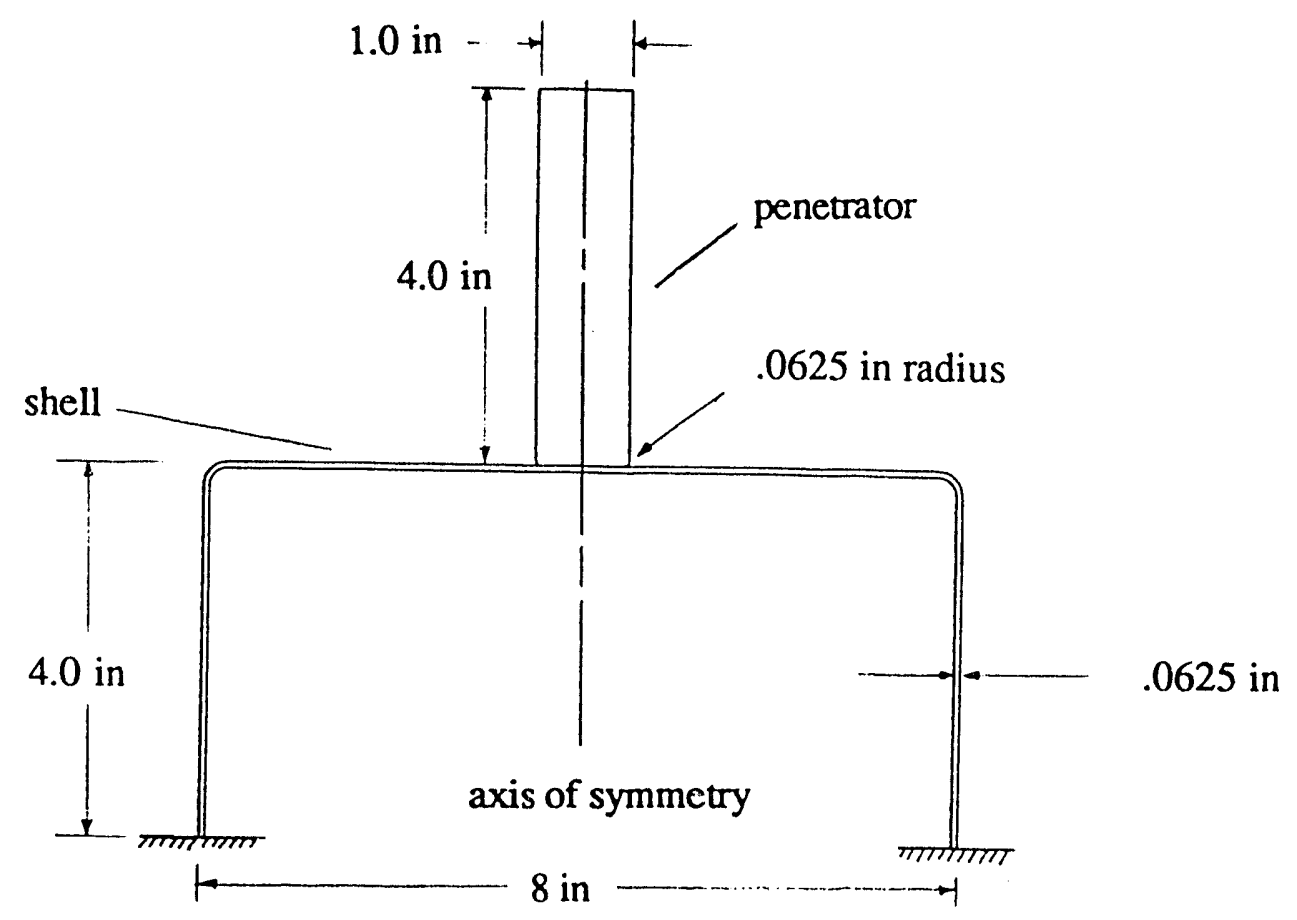

Figure 1. Geometry selected for this study. 
Table 1. Constant material values (based on SS304L).

\begin{tabular}{|c|c|}
\hline $\mathrm{E}$ & $30.0^{*} 10^{6} \mathrm{psi}$ \\
\hline Poiison's ratio & 0.30 \\
\hline initial temperature & $293 \mathrm{~K}$ \\
\hline density & $7.35^{*} 10^{-4} \mathrm{lbs}^{*} \mathrm{~s}^{2} / \mathrm{in}$ \\
\hline $\mathrm{c} 2$ & $0 . \mathrm{K}$ \\
\hline $\mathrm{c} 4$ & $4.68^{*} 10^{2} \mathrm{~K}$ \\
\hline $\mathrm{c} 5$ & $7.04^{*} 10^{-6} \mathrm{~s}-1$ \\
\hline $\mathrm{c} 6$ & $0 . \mathrm{K}$ \\
\hline $\mathrm{c} 7$ & $5.72^{*} 10^{-4}(\mathrm{psi})^{-1}$ \\
\hline $\mathrm{c} 8$ & $1.23 \mathrm{~K}$ \\
\hline $\mathrm{c} 9$ & $8.7^{*} 10^{4} \mathrm{psi}$ \\
\hline $\mathrm{c} 10$ & $0 . \mathrm{K}$ \\
\hline $\mathrm{c} 11$ & $0 .\left(\mathrm{psi} \mathrm{i}^{*} \mathrm{~s}\right)^{-1}$ \\
\hline $\mathrm{c} 12$ & $0 . \mathrm{K}$ \\
\hline $\mathrm{c} 14$ & $7.01 \mathrm{~K}$ \\
\hline $\mathrm{c} 16$ & $0 . \mathrm{K}$ \\
\hline $\mathrm{c} 18$ & $6.79^{*} 10^{3} \mathrm{~K}$ \\
\hline
\end{tabular}

Note: base units in lbs, in, $s, K$.

\subsection{Analysis matrix, selected factors and their levels.}

The eight material properties selected for this study were: two yield strength parameters ( $Y$ and $V$ ), hardening $(H)$, static and dynamic recovery $\left(R_{S}\right.$ and $\left.R_{d}\right)$, initial porosity, damage exponent, and heat generation coefficient. A copy of the model theory with definitions for these properties (Ref. 4) is included in Appendix A. Appendix B shows effects on the inelastic characteristics of the model for five of these selected parameters.

We planned the analysis matrix using the design of experiment technique. This technique effectively changed levels of several properties simultaneously throughout the matrix. An L18 Taguchi matrix was selected to investigate main effects of 8 factors, one factor at two levels, and seven factors at three levels. Each factor was used for each of the eight selected properties. We assumed that interaction effects were secondary to main effects. The simplicity of this screening study justified this assumption. Table 2 shows the L18 matrix, which defined required combinations of levels for the selected eight material properties for each of the 18 trial runs.

The Sandia plasticity/damage model allows for temperature dependency through material parameter definitions. Of those selected parameters in this study, $\mathrm{R}_{\mathrm{S}}, \mathrm{Y}, \mathrm{V}, \mathrm{H}$, and $R_{d}$ were temperature dependent. Their definition has the form:

$$
\mathrm{c}_{\mathrm{i}}(\mathrm{cj} / \theta)
$$


where $c_{i}$ and $c_{j}$ are input parameters and $\theta$ is the temperature. In this study, we did not examine temperature effects. The level of each selected parameter was adjusted by changing the $c_{i}$ terms; the $c_{j}$ terms were kept constant. Thus, only parameters $c_{1}, c_{3}$, $c_{13}, c_{15}$ and $c_{17}$ were used to change levels of yield $\mathrm{Y}$, yield $\mathrm{V}$, dynamic recovery $\mathrm{Rd}$, hardening $\mathrm{H}$, and static recovery Rs respectively (See Appendix A).

Table 2. L18 matrix and trial run results.

\begin{tabular}{|c|c|c|c|c|c|c|c|c|c|}
\hline $\begin{array}{c}\text { Trial } \\
\text { Run }\end{array}$ & Rs & Y & V & H & Rd & $n$ & p & Ho & $\begin{array}{c}\text { Failure } \\
\text { vel. } \\
\text { in/s). }\end{array}$ \\
\hline & & & & & & & & & \\
\hline 1 & A & A & A & A & A & A & A & A & 3000 \\
\hline 2 & A & A & B & B & B & B & B & B & 2300 \\
\hline 3 & A & A & C & C & C & C & C & C & 3300 \\
\hline 4 & A & B & A & A & B & B & C & C & 1400 \\
\hline 5 & A & B & B & B & C & C & A & A & 4000 \\
\hline 6 & A & B & C & C & A & A & B & B & 2200 \\
\hline 7 & A & C & A & B & A & C & B & C & 3900 \\
\hline 8 & A & C & B & C & B & A & C & A & 3400 \\
\hline 9 & A & C & C & A & C & B & A & B & 1600 \\
\hline 10 & B & A & A & C & C & B & B & A & 3100 \\
\hline 11 & B & A & B & A & A & C & C & B & 2400 \\
\hline 12 & B & A & C & B & B & A & A & C & 3600 \\
\hline 13 & B & B & A & B & C & A & C & B & 2000 \\
\hline 14 & B & B & B & C & A & B & A & C & 2800 \\
\hline 15 & B & B & C & A & B & C & B & A & 2000 \\
\hline 16 & B & C & A & C & B & C & A & B & 2000 \\
\hline 17 & B & C & B & A & C & A & B & C & 2200 \\
\hline 18 & B & C & C & B & A & B & C & A & 4200 \\
\hline
\end{tabular}

We chose levels for each selected material property by deviating from existing data for SS304L. The magnitude of the deviations were based on what we thought were achievable. Table 3 shows the eight selected factors and their $c_{i}$ levels.

\subsection{Finite element modeling}

The finite element code DYNA2D was used for this study. We included slide lines on the penetrator and the shell outer surface to model the material interface. The penetrator was the master surface, and the shell was the slave surface. Figure 2 shows the finite element mesh used in all analyses.

The penetrator was given an initial velocity to start each analysis. We ran each analysis until the penetrator either had penetrated through the shell or had rebounded off the shell. 
Table 3. Selected factors and their ci levels.

\begin{tabular}{|c|c|c|c|}
\hline Factor & Level A & Level B & Level C \\
\hline & & & \\
\hline Static recovery, $\mathrm{R}_{\mathrm{S}}\left(\mathrm{psi}{ }^{*} \mathrm{~s}\right)^{-1}$ & $4.77^{*} 10^{-7}$ & $4.29 * 10^{-6}$ & none \\
\hline Yield, $\mathrm{Y}(\mathrm{psi})$ & $6.97 * 10^{+3}$ & $3.49 * 10^{+4}$ & $2.09 * 10^{+4}$ \\
\hline Yield, $\mathrm{V}(\mathrm{psi})$ & $8.93 * 10^{+2}$ & $4.47 * 10^{+3}$ & $2.68 * 10^{+3}$ \\
\hline Hardening, $\mathrm{H}(\mathrm{psi})$ & $5.50^{*} 10^{+4}$ & $4.95 * 10^{+5}$ & $2.75 * 10^{+5}$ \\
\hline Dynamic recovery, $\mathrm{R}_{\mathrm{d}}(\mathrm{psi})^{-1}$ & $1.50^{*} 10^{-4}$ & $1.35^{*} 10^{-3}$ & $7.50^{*} 10^{-4}$ \\
\hline Damage exponent, $\mathrm{n}$ & $4.70^{*} 10^{+0}$ & $7.05 * 10^{+0}$ & $5.88^{*} 10^{+0}$ \\
\hline Initial porosity, $\mathrm{p}$ & $1.00^{*} 10^{-4}$ & $1.00^{*} 10^{-3}$ & $5.50^{*} 10^{-4}$ \\
\hline Heat coefficient, $\mathrm{H}_{\mathrm{o}}(\mathrm{K} / \mathrm{psi})$ & $0.00^{*} 10^{+0}$ & $3.00^{*} 10^{-3}$ & $1.50^{*} 10^{-3}$ \\
\hline
\end{tabular}

Note: base units in lbs, in, $s, K$

Effects of material properties on the penetration resistance were measured in terms of failure velocity. We defined the failure velocity as the minimum initial velocity required for the penetrator to penetrate the shell. This minimum velocity was required for each trial run of the L18 matrix. Since each analysis ended as a failure (penetrated) or a no failure (rebounded), we had to iterate an analysis several times to determine the failure velocity for each trial run. On the average, each trial run took about five iterations to determine a failure velocity that had a $100 \mathrm{in} / \mathrm{s}$ uncertainty.

The Sandia plasticity/damage model tracks a damage coefficient to predict void growth. Voids grow to degrade material properties and increase the damage coefficient. Complete failure in a finite element (tearing) is predicted when this damage coefficient reaches a critical value (.99). Penetration of the shell occurred when there existed a continous path of failed elements through the shell's thickness. Figure 3 shows a deformed shell, and Figure 4 shows a penetrated shell.

\section{Results}

The last column in Table 2 shows the failure velocity for each of the 18 trial runs. The average failure velocity for these 18 runs was $2740 \mathrm{in} / \mathrm{s}$.

Table 4 shows the average failure velocity for each level of each factor. For any level of any factor, the value in Table 4 was obtained by taking the average of failure velocities of all the runs that had that particular factor set at that particular level. For example, the average failure velocity of level $\mathrm{B}$ of factor $\mathrm{H}$ was determined by taking the average of runs $2,5,7,12,13$, and 18 .

Table 5 shows the relative importance for each factor level. This table shows relative effects of material properties on the shell's tearing resistance. We obtained the results in this table by subtracting the average failure velocity, $2740 \mathrm{in} / \mathrm{s}$, from respective values of Table 4 . 

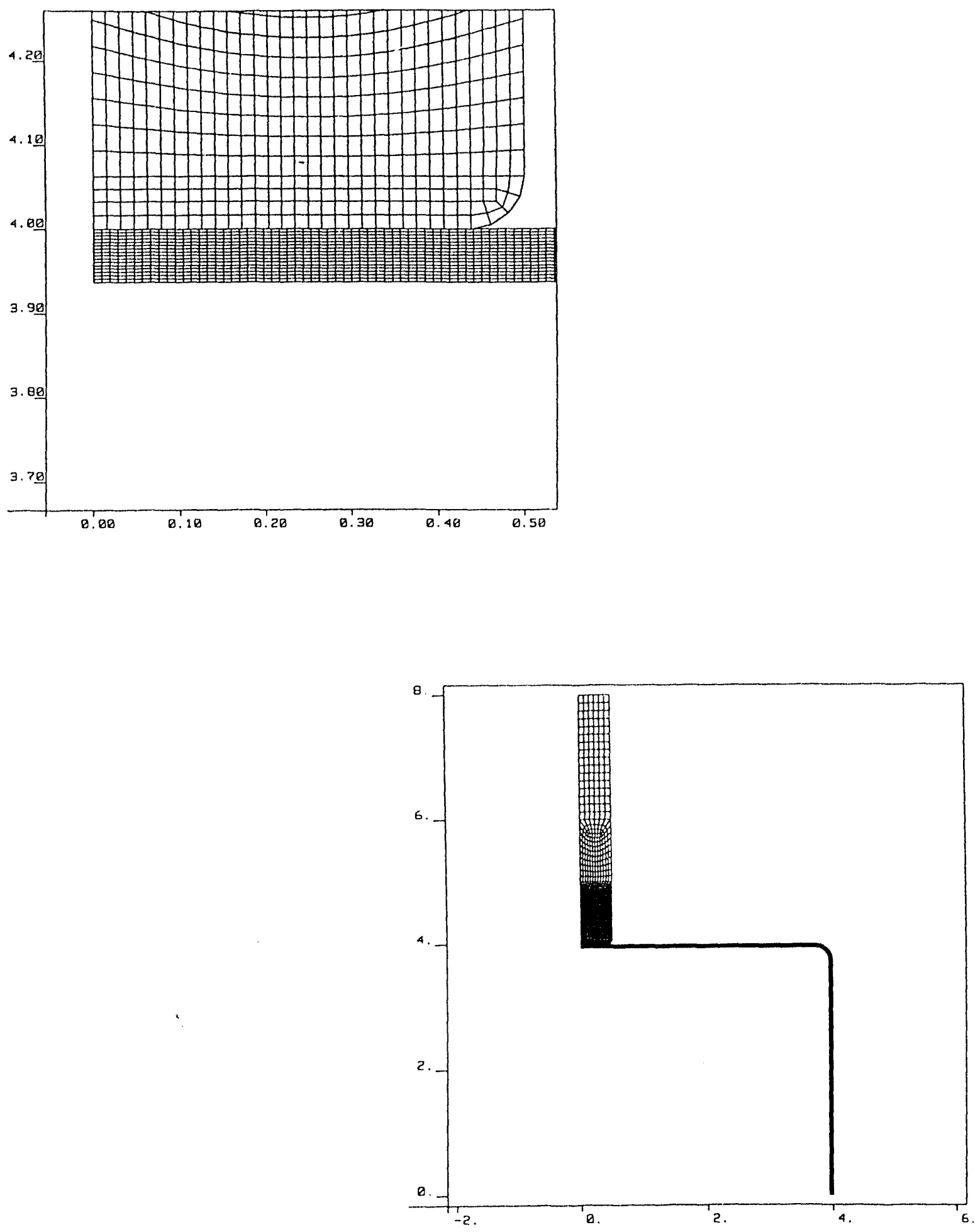

Figure 2. Finite element mesh used in all analyses. 


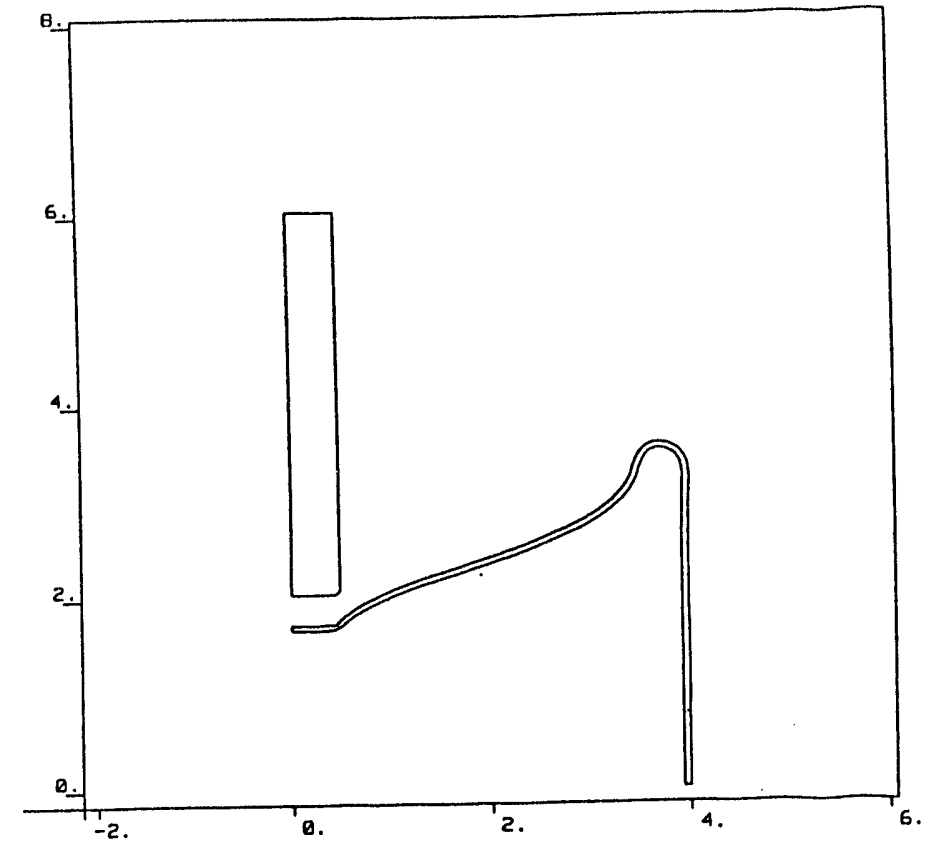

Figure 3. A deformed but not penetrated shell.

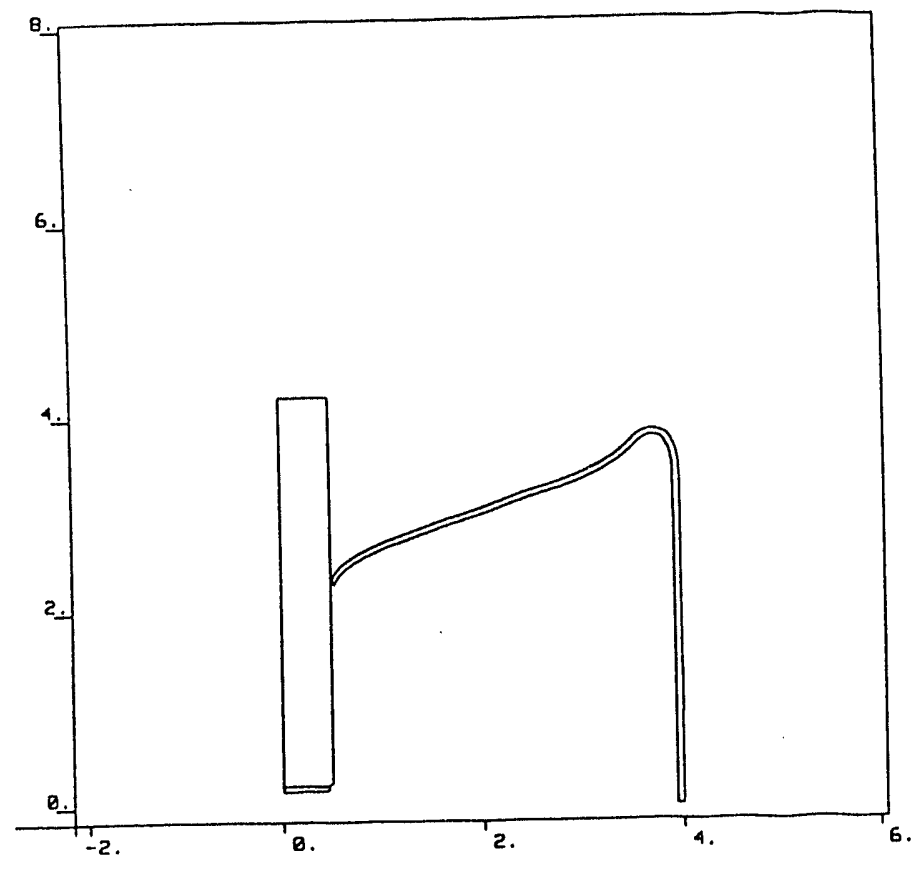

Figure 4. A penetrated shell. 11 
Table 4. Average failure velocity of the factors and their levels (in/s).

\begin{tabular}{|c|c|c|c|c|c|c|c|c|}
\hline Level & Rs & Y & V & H & Rd & n & p & Ho \\
\hline & & & & & & & & \\
\hline A & 2789 & 2950 & 2567 & 2100 & 3083 & 2733 & 2833 & 3283 \\
\hline B & 2700 & 2400 & 2850 & 3333 & 2450 & 2567 & 2617 & 2083 \\
\hline C & & 2883 & 2817 & 2800 & 2700 & 2933 & 2783 & 2867 \\
\hline
\end{tabular}

Table 5. Relative effects of the factors and their levels (in/s).

\begin{tabular}{|c|c|c|c|c|c|c|c|c|}
\hline Level & Rs & Y & V & H & Rd & n & p & Ho \\
\hline & & & & & & & & \\
\hline A & 44 & 206 & -178 & -644 & 339 & -11 & 89 & 539 \\
\hline B & -44 & -344 & 106 & 589 & -294 & -178 & -128 & -661 \\
\hline C & & 139 & 72 & 56 & -44 & 189 & 39 & 122 \\
\hline
\end{tabular}

Figure 5 summarizes major results of this study. The bars in this plot show effects of selected material properties on the she!l's tearing resistance as measured by the failure velocity. The length of the bar between two levels of a factor shows the change in failure velocity from changing the level of that factor. An increase in failure velocity means higher tearing resistance for the shell.

From Figure 5, we see $\mathrm{H}$ and $\mathrm{H}_{\mathrm{O}}$ had the largest effects. Effect of $\mathrm{Y}$ and $\mathrm{R}_{\mathrm{d}}$ was about one half of the effect of $\mathrm{H}$ and $\mathrm{H}_{\mathrm{O}}$. $\mathrm{R}_{\mathrm{S}}$ showed almost no effect and $\mathrm{V}, \mathrm{n}$ and $\mathrm{p}$ showed relatively little effects.

Figure 6 shows plots of failure velocities versus selected levels for each examined factor. For three level factors, these plots also show the degree of linearity of their responses. In all factors, level A was the lowest level, level B was the highest level, and level $\mathrm{C}$ was in the midle. The nonlinearities in some factors $(\mathrm{Y}, \mathrm{V}, \mathrm{n})$ suggest interactions between the factors.

Results of the L18 matrix can be used to form a model to predict failure velocities for other combinations of selected material properties. To do this, one takes the average failure velocity $(2740 \mathrm{in} / \mathrm{s})$ and adds contributions (Table 5) of selected levels for each of the eight examined material properties. The following example illustrates this prediction capability.

According to the results (Table 5 or Figure 5), the combination that would produce the highest failure follows: $\mathrm{R}_{\mathrm{S}}, \mathrm{Y}, \mathrm{R}_{\mathrm{d}}, \mathrm{p}$ and $\mathrm{H}_{\mathrm{O}}$ at level $A ; \mathrm{V}$ and $\mathrm{H}$ at level $B$; and only $\mathrm{n}$ at level $C$. The failure velocity (in/s) for this "strongest" combination is calculated from the L18 model as follow:

$$
2740+44+206+106+589+339+189+89+539=5417
$$




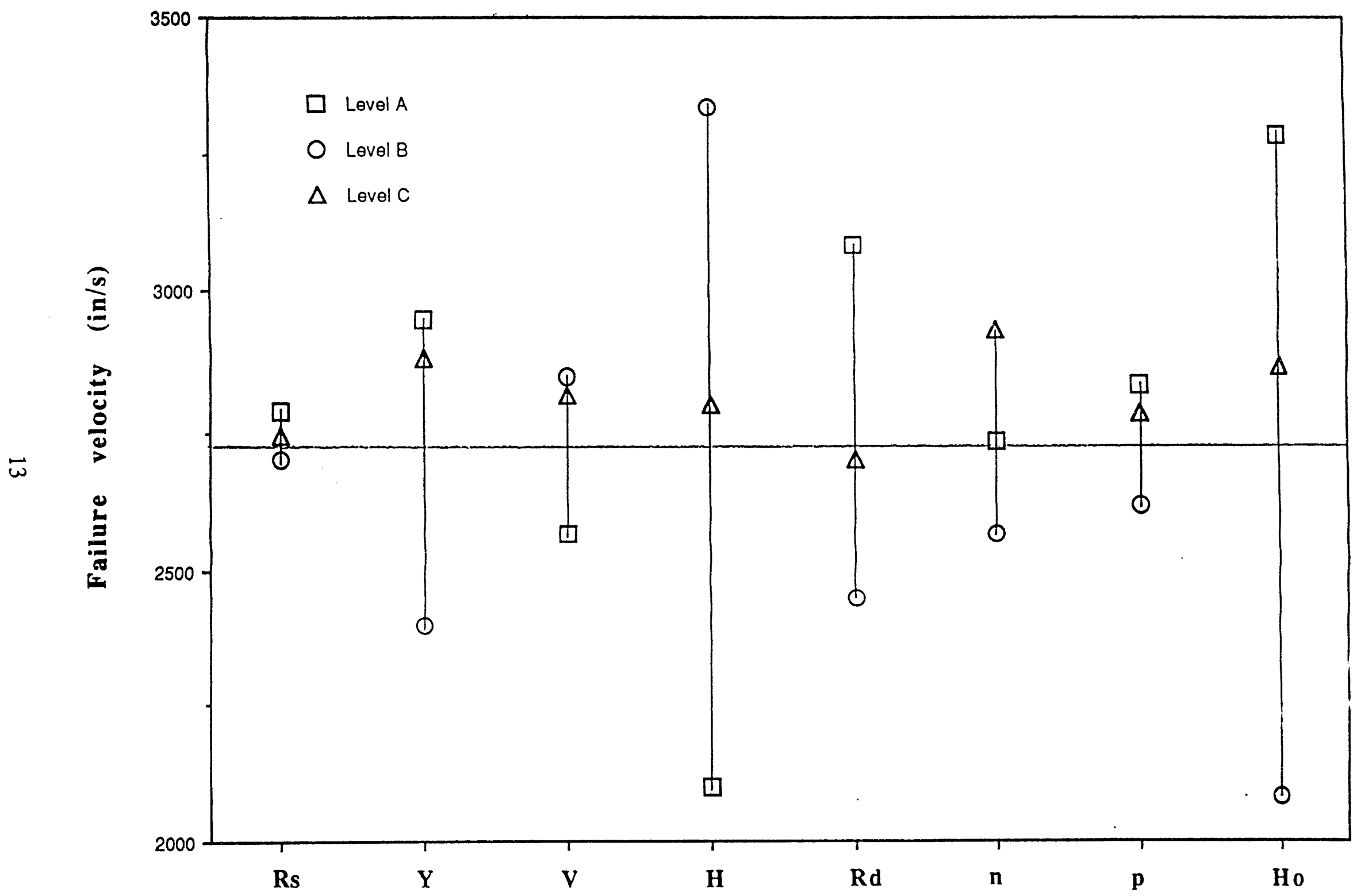

Figure 5. Effects of selected properties on shell's penetration resistance. 

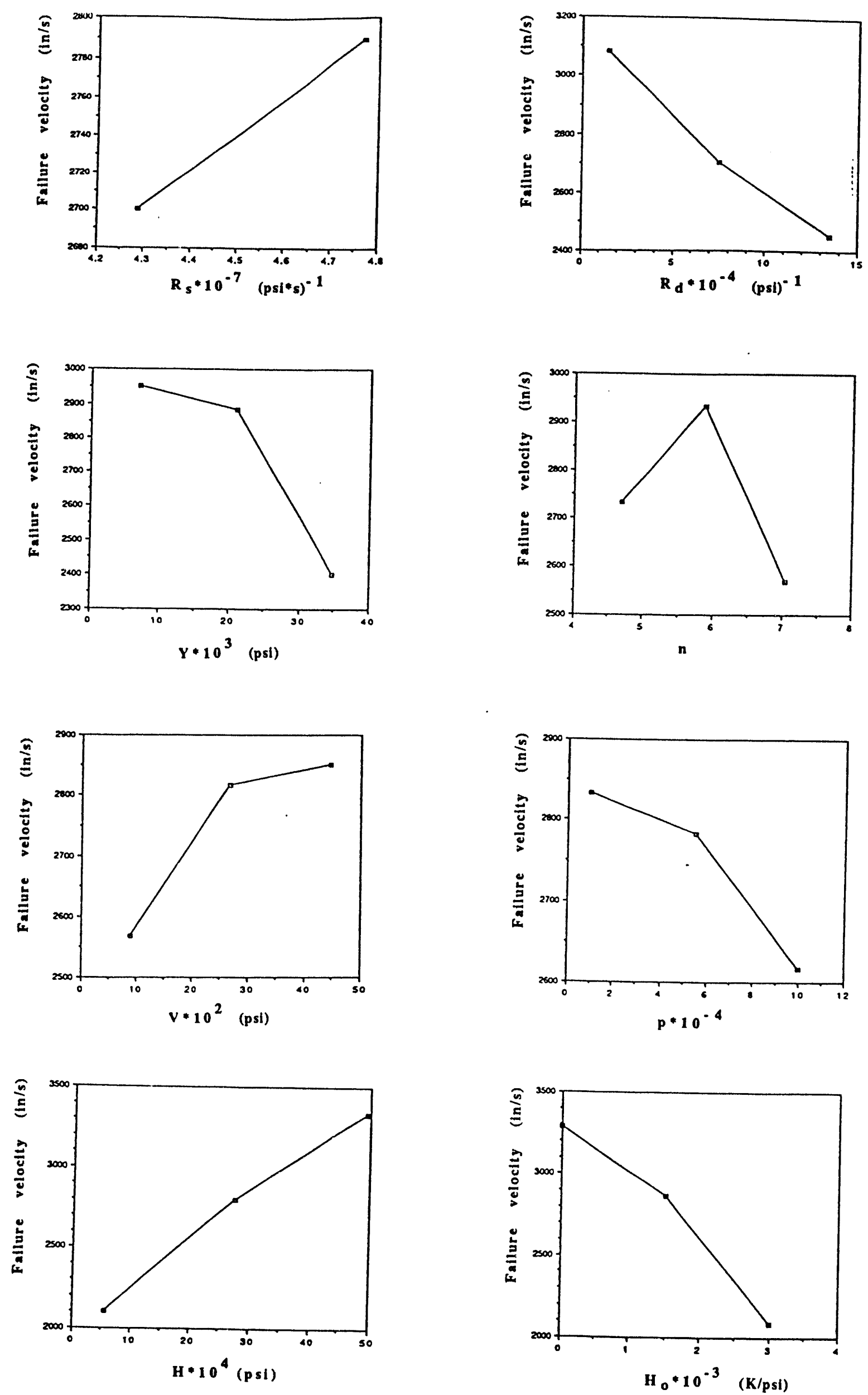

Figure 6. Failure velocity at different levels for each selected property. 
We ran a confirmation finite element analysis for this best combination to verify the $\mathrm{L} 18$ results. The minimum initial velocity needed for penetration was $5700 \mathrm{in} / \mathrm{s}$ (to the nearest $100 \mathrm{in} / \mathrm{s})$. A 5\% difference between the prediction from the L18 model and the finite element analysis supported the design of experiment results.

\section{Discussions}

The ranges selected for levels of the examined factors played a large role in the outcome of this study. For example, if the range of the dynamic recovery $\left(R_{d}\right)$ was twice as large, its effect would likely double. If this is true, its effect would be equal to that of the hardening $(\mathrm{H})$ and the heat generation $\left(\mathrm{H}_{0}\right.$, see Figure 5), the two most important properties according to the obtained results. Therefore, the relative results with respect to the selected ranges for the various properties are more useful than the absolute results. Although levels of examined properties were hypothetical, we chose realistic numbers to bound the property effects.

The selected simple geometry allowed for the use of inexpensive twodimensional (2D) analyses. This study focused on material and not geometry effects. We assumed that the selected geometry, which lacked geometry effects of a 3D event, had little influence on the results. We believe the material results obtained here are true in general, and not restricted to $2 \mathrm{D}$ events.

Without laboratory verification, the validity of these results rest entirely on the validity of the Sandia plasticity/damage model. The model has compared well with similar penetration studies (Ref.5), which considered the same type of thin shell penetration. This model has also done well in many other impact. studies that involved thin shells and extreme loads (high velocity projectile, pressure loads from explosions, etc.; see Ref. 2)

A firing set housing is packed with electronic and mechanical components. For simplification, we did not examine effects of internal components and partitions. We plan to examine these effects in future studies, which would involve 3D modeling.

\section{Conclusion}

We successfully quantified effects of eight selected material properties on the penetration resistance of the examined cylindrical shell. For the examined system (selected geometry and ranges of properties), the hardening $(\mathrm{H})$ and the heat generation $\left(\mathrm{H}_{\mathrm{O}}\right)$ parameters contributed most to the penetration resistance of the shell. The static recovery $\left(R_{S}\right)$ parameter had no significant effect. Figure 5 summarizes the influences on the shell's penetration resistance of the eight examined properties.

Results obtained here can be used to improve or assess the penetration resistance of metallic housing structures. These screening results can also be used to plan for more detailed and more comprehensive material studies. 


\section{References}

1. Hallquist, J. O., "User's Manual for Dyna2D- An Explicit Two Dimensional Hydrodynamic Finite Element Code with Interactive Rezoning and Graphical Display," Lawrence Livermore National Laboratory Report, UCID-18756-Rev 3.

2. D. J. Bamman, M. L. Chiesa, et. al., "Prediction of Ductile Failure in Metal Structures, " paper presented at the winter annual meeting of the American Society of Mechanical Engineers, Dallas, Texas, AMD-Vol. 107, November 25-30, 1990.

3. P. J. Ross, "Taguchi Techniques for Quality Engineering-- Loss Function, Orthogonal Experiments, Parameter and Tolerance Design," McGraw-Hill Book Company, New York, 1988.

4. D. J. Bammann, M. L. Chiesa, J. F. Lathrop, "Sandia Damage Model Implementation in PRONTO3D and JAC3D," Draft of a Sandia technical report to be published, Sandia National Laboratories, Livermore, CA, 1992.

5. K. V. Trinh, J. D. Gruda, "Failure Resistance of Thin Shells Against Projectile Penetration," Sandia report SAND91-8486, Sandia National Laboratories, Livermore, CA, July, 1991.

6. J. F. Lathrop, "BFIT - a program to analyze and fit the Sandia plasticity (Bammann) model parameters to experimental data", a preliminary users guide for the BFIT program, Sandia National Laboratories, Livermore, CA, July, 1993. 


\section{Appendix A}

Sandia plasticity/damage model for ductile metals. Reproduced from pages 3,4, and 7 of Reference 4. 
Introduction

\section{The Model}

The model assumes the strain rate $D$ can be decomposed into elastic and plastic parts

$$
D=D^{e}+D^{p}
$$

and that the elastic part obeys the linear relation:

$$
\stackrel{\circ}{\sigma}=(1-\phi)\left(\lambda \operatorname{tr}\left(D^{e}\right) I+2 \mu D^{e}\right)-\frac{\dot{\phi}}{(1-\phi)} \sigma
$$

where the Cauchy stress is convected with the elastic spin.

$$
\stackrel{\circ}{\sigma}=\dot{\sigma}-W^{e} \sigma+\sigma W^{e}
$$

The model assumes a flow rule of the form

$$
D^{p}=f(\theta) \sinh \left[\frac{\sqrt{\frac{3}{2}}|\xi|-k-Y(\theta)}{V(\theta)(1-\phi)}\right] \frac{\xi}{|\xi|}
$$

where $\xi=\sigma^{\prime}-\frac{2}{3} \alpha$ and the internal variables, the backstress tensor $\alpha$, the hardening scalar $k$, and the void scalar $\phi$ are given by the evolution rules:

$$
\begin{gathered}
\dot{\alpha}=h(\theta) D^{p}-\left[r_{d}(\theta)\left|D^{p}\right|+r_{s}(\theta)\right] \sqrt{\frac{2}{3}}|\alpha| \alpha \\
\dot{k}=H(\theta)\left|D^{p}\right|-\left[R_{d}(\theta)\left|D^{p}\right|+R_{s}(\theta)\right] k^{2} \\
\dot{\phi}=\beta\left[\frac{1}{(1-\phi)^{n}}-(1-\phi)\right]\left|D^{p}\right|
\end{gathered}
$$


The Model

$$
\beta=\sinh \left[\frac{2(2 n-1) p}{(2 n+1) \bar{\sigma}}\right]
$$

where $\bar{\sigma}$ is effective stress, $p$ the mean stress, $\theta$ the temperature, $h, H, r_{s}, r_{d} R_{s}, R_{d}$, are the temperature dependent plasticity parameters of the form $c_{1} \exp \left( \pm \frac{c_{2}}{\theta}\right)$, and $n$ is the void growth parameter. 


\section{Input}

To describe a material in PRONTO3D using the damage model, the material definition section needs to define the following;

Youngs modulus

Poissons ratio

Initial Temperature

Thermal expansion

coefficient of thermal expansion

Damage constant

" $n$ " in the equations

Initial damage

initial value of $\phi$

Heat coefficient

$\frac{0.9}{\rho C_{\nu}}$ heai due to plastic work

$\mathrm{c1}, \mathrm{c} 2$

$V=c 1 \exp (-\mathrm{c} 2 / \theta)$

c3,c4

$Y=c 3 \exp (\mathrm{c} 4 / \theta)$

$\mathrm{c} 5, \mathrm{c} 6$

$f=c 5 \exp (-c 6 / \theta)$

$\mathrm{c7,c8}$

$r_{d}=c 7 \exp (-\mathrm{c} 8 / \theta)$

c9,c10

$h=c 9 \exp (\mathrm{cl} / 0 / \theta)$

c11, c12

$r_{s}=c 11 \exp (-\mathrm{c} 12 / \theta)$

c13,c14

$R_{d}=c 13 \exp (-\mathrm{cl} 14 / \theta)$

c15,c16

$H=c 15 \exp (\mathrm{c} 16 / \theta)$

$\mathrm{c} 17, \mathrm{c} 18$

$R_{s}=c 17 \exp (-\mathrm{c} 18 / \theta)$

It should be noted that for now the thermal expansion term is not used. Also the initial damage term must be non-zero for any damage to develop. 


\section{Appendix B}

Effects of c1, c3, c13, c15 and c17 on the inelastic characteristics of the Sandia plasticity/damage model.

Plots presented here were generated using the Bfit program (Reference 6). 
Changing $\mathrm{C} 1$ while holding other parameters constant Unit system: Ibf, inch, second, Kelvin.

$\begin{array}{lll}c 1=\text { variable } & c 7=0.000572 & c 13=0.00075 \\ c 2=0 & c 8=1.23 & c 14=7.01 \\ c 3=2.09 e+04 & c 9=8.7 e+04 & c 15=2.75 e+05 \\ c 4=468 & c 10=0 & c 16=0 \\ c 5=7.04 e-06 & c 11=0 & c 17=2.38 e-06 \\ c 6=0 & c 12=0 & c 18=6790\end{array}$

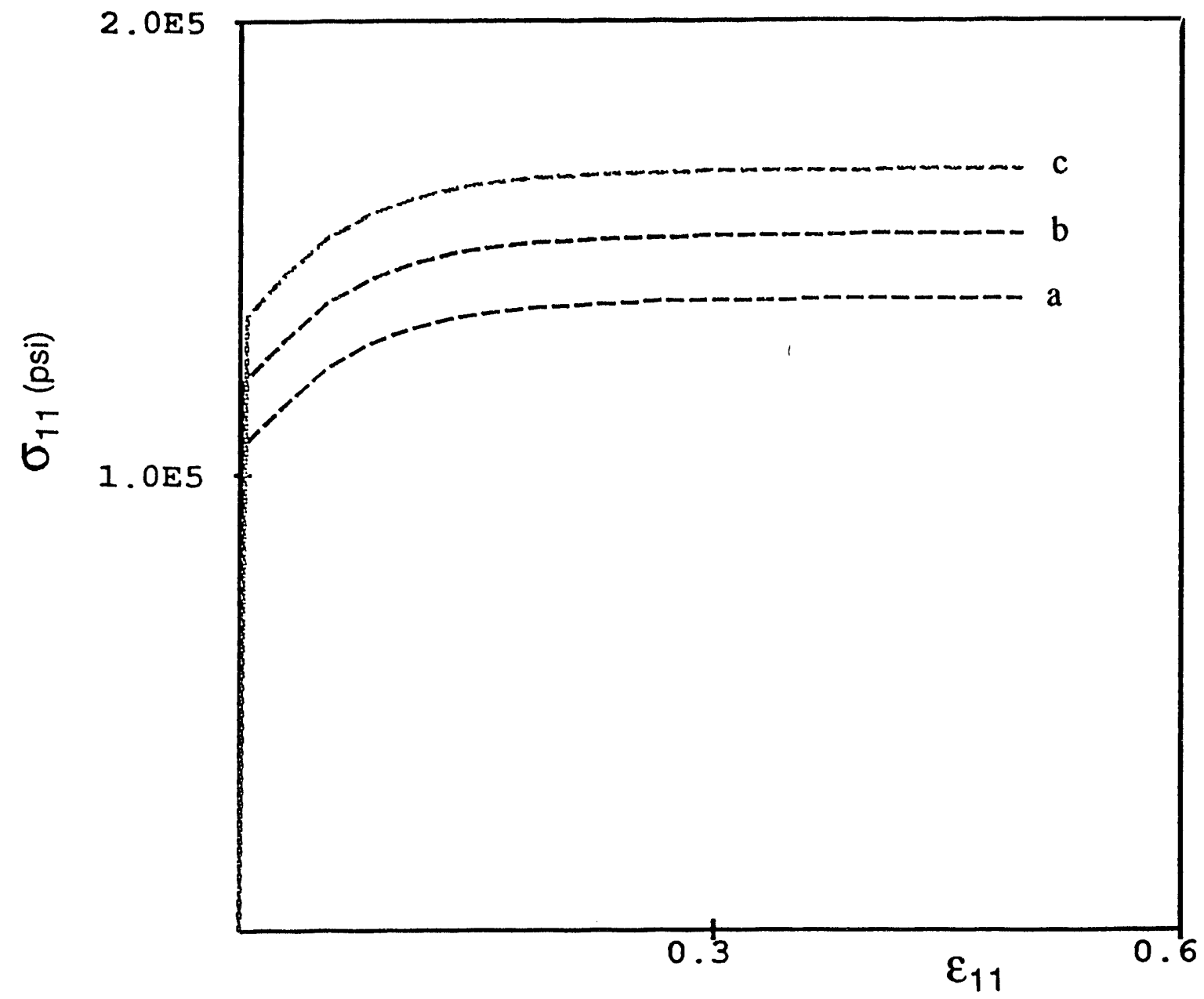

Parameter C1 (psi), rate $=0.01 \mathrm{~s}-1$
a 893.
b 2681 .
c 4470 . 
Changing C3 while holding other parameters constant Unit system: Ibf, inch, second, Kelvin.
c1 $=4470$
$c 7=0.000572$
$c 13=0.00075$
$\mathrm{c} 2=0$
$c 8=1.23$
c14 $=7.01$
c3 = variable
c9 $=8.7 e+04$
$c 15=2.75 e+05$
$c 4=468$
c10 $=0$
c16 $=0$
c5 $=7.04 \mathrm{e}-06$
c11 $=0$
$\mathrm{c} 17=2.38 \mathrm{e}-06$
c6 $=0$
c12 $=0$
$c 18=6790$

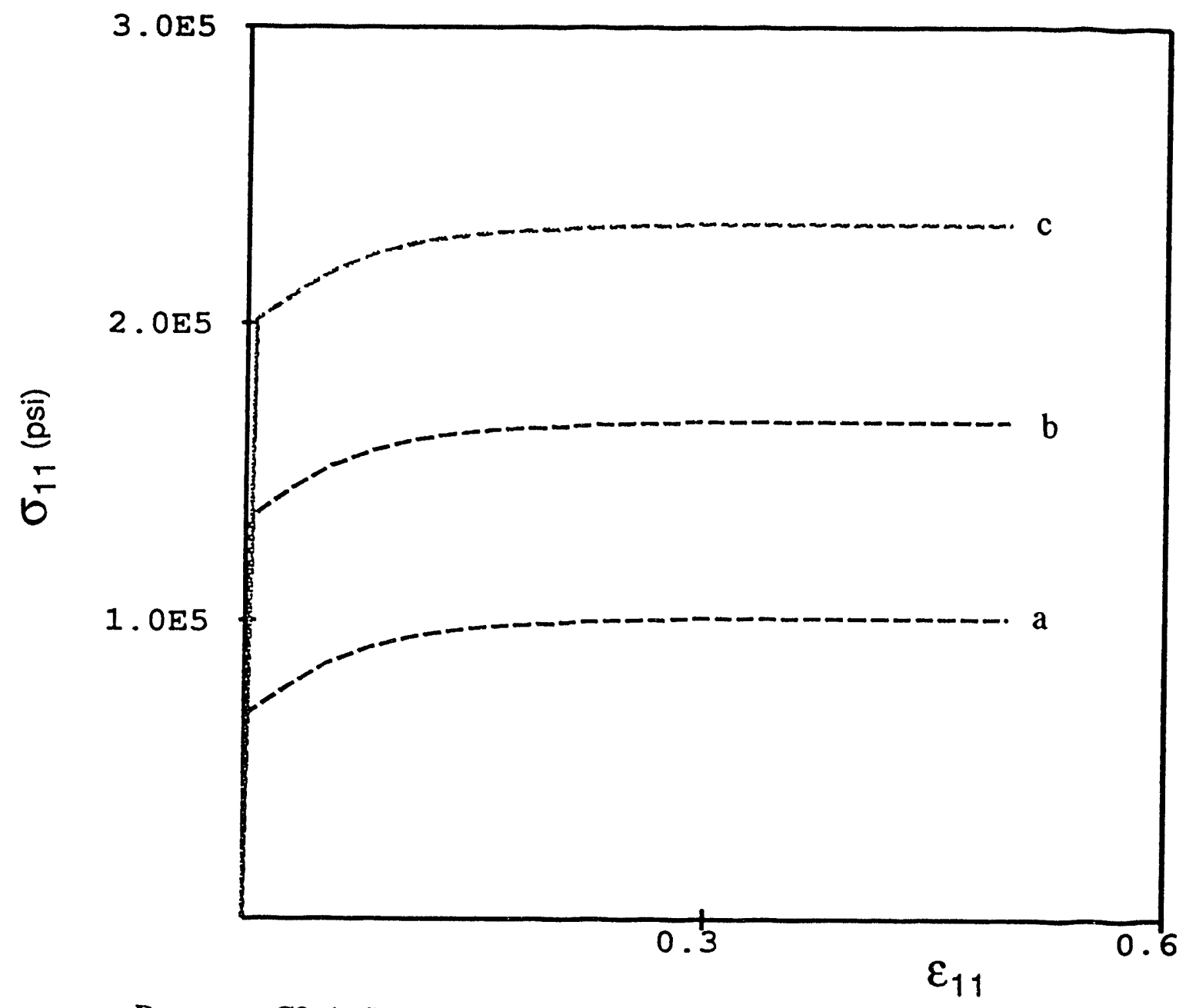

Parameter C3 (psi), rate $=0.01 \mathrm{~s}-1$
a 6970.
b 20,935 .
c 34,900 . 
Changing $\mathrm{C13}$ while holding other parameters constant Unit system: Ibf, inch, second, Kelvin.

$$
\begin{array}{lll}
c 1=4470 & c 7=0.000572 & c 13=\text { variable } \\
c 2=0 & c 8=1.23 & c 14=7.01 \\
c 3=3.49 e+04 & c 9=8.7 e+04 & c 15=2.75 e+05 \\
c 4=468 & c 10=0 & c 16=0 \\
c 5=7.04 e-06 & c 11=0 & c 17=2.38 e-06 \\
c 6=0 & c 12=0 & c 18=6790
\end{array}
$$

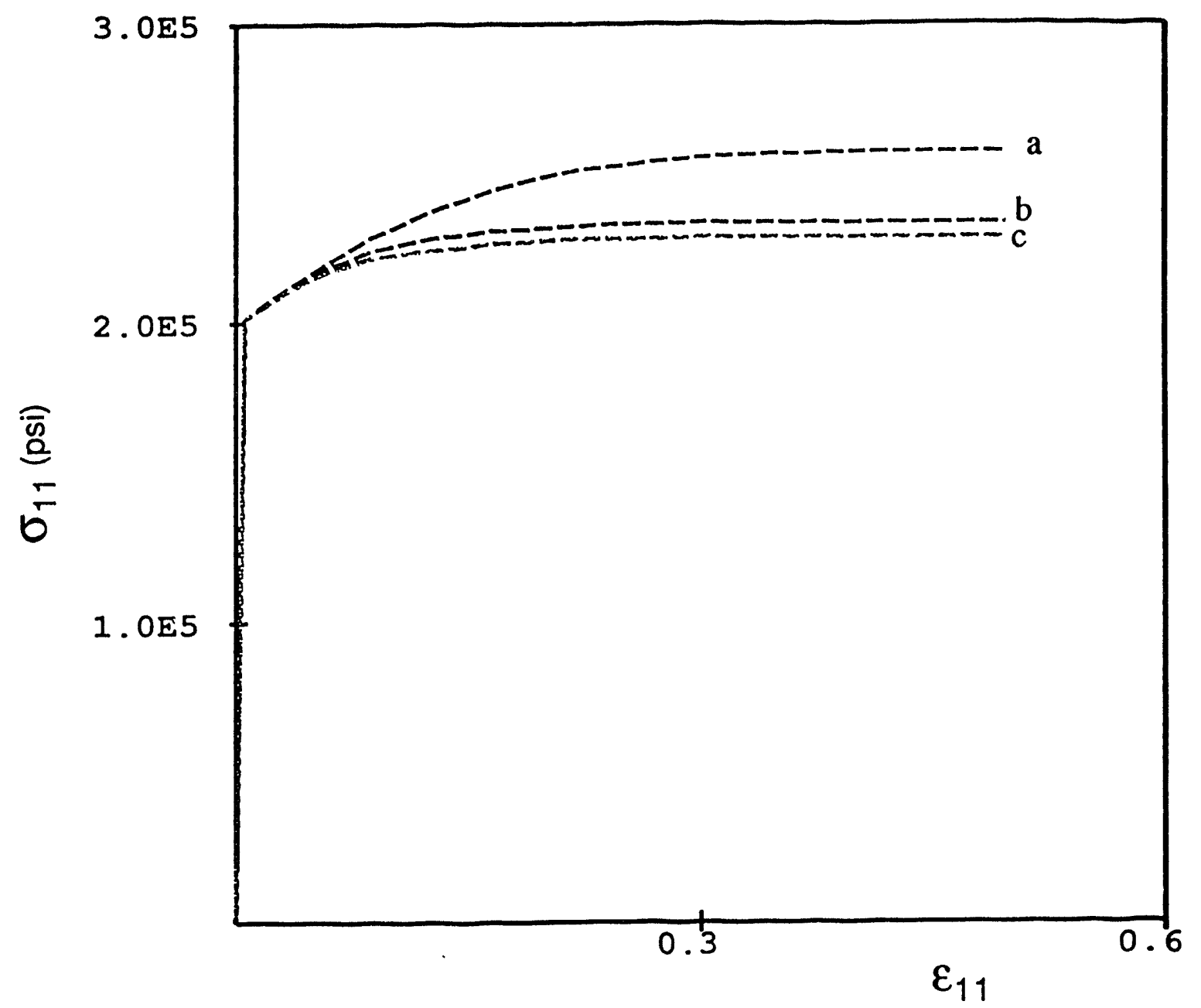

Parameter $\mathrm{C} 13(\mathrm{psi})^{-1}$, rate $=0.01 \mathrm{~s}-1$
a .00015
b .00075
c .00135 
Changing C15 while holding other parameters constant Unit system: lbf, inch, second, Kelvin.

$$
\begin{array}{lll}
c 1=4470 & c 7=0.000572 & c 13=0.00135 \\
c 2=0 & c 8=1.23 & c 14=7.01 \\
c 3=3.49 e+04 & c 9=8.7 e+04 & c 15=\text { variable } \\
c 4=468 & c 10=0 & c 16=0 \\
c 5=7.04 e-06 & c 11=0 & c 17=2.38 e-06 \\
c 6=0 & c 12=0 & c 18=6790
\end{array}
$$

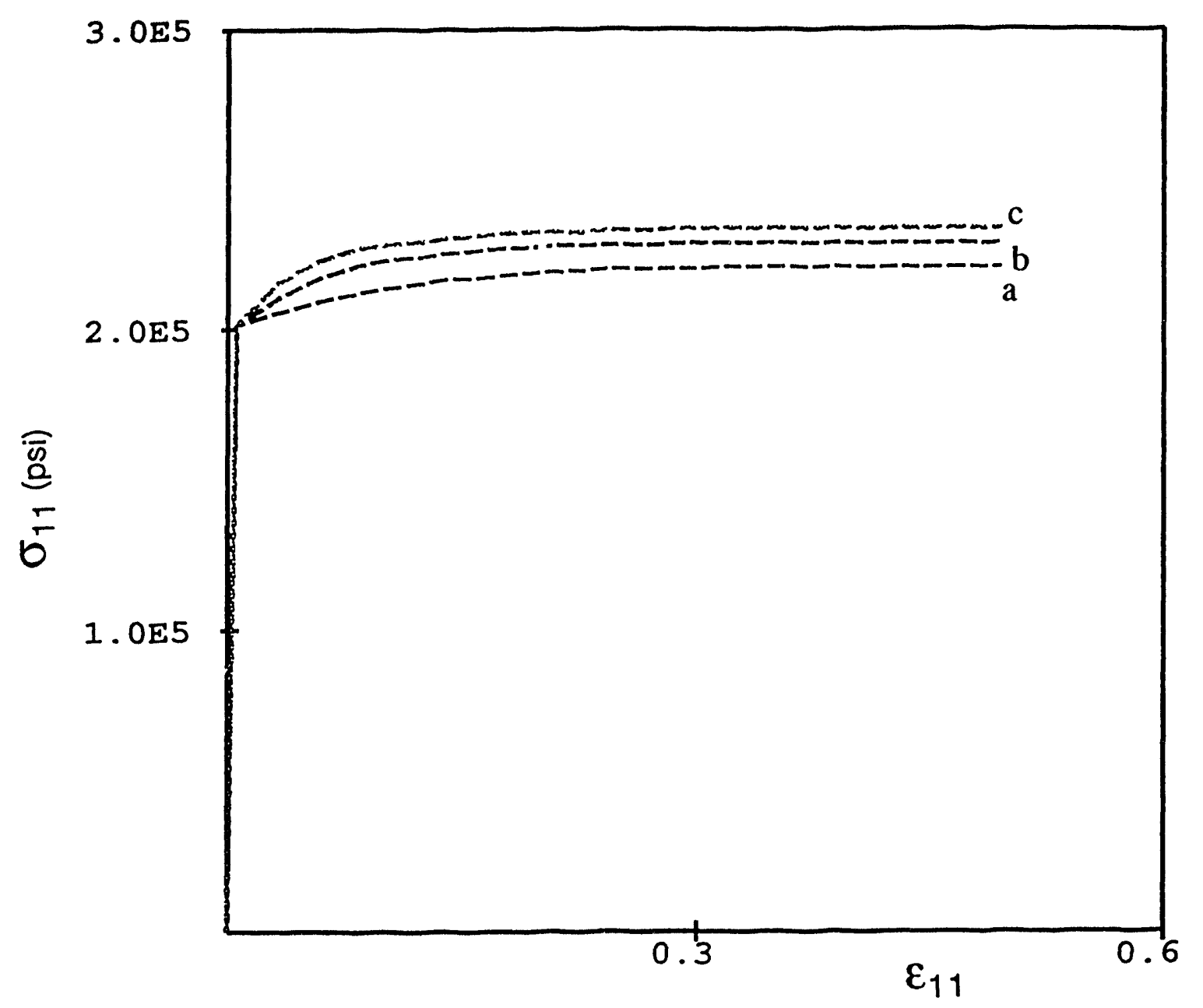

Parameter C15 (psi), rate $=0.01 \mathrm{~s}-1$
a 55,000 .
b 275,000 .
c 495,000 . 
Changing $\mathbf{C 1 7}$ while holding other parameters constant Unit system: lbf, inch, second, Kelvin.

$$
\begin{array}{lll}
c 1=4470 & c 7=0.000572 & c 13=0.00135 \\
c 2=0 & c 8=1.23 & c 14=7.01 \\
c 3=3.49 e+04 & c 9=8.7 e+04 & c 15=4.95 e+05 \\
c 4=468 & c 10=0 & c 16=0 \\
c 5=7.04 e-06 & c 11=0 & c 17=\text { variable } \\
c 6=0 & c 12=0 & c 18=6790
\end{array}
$$

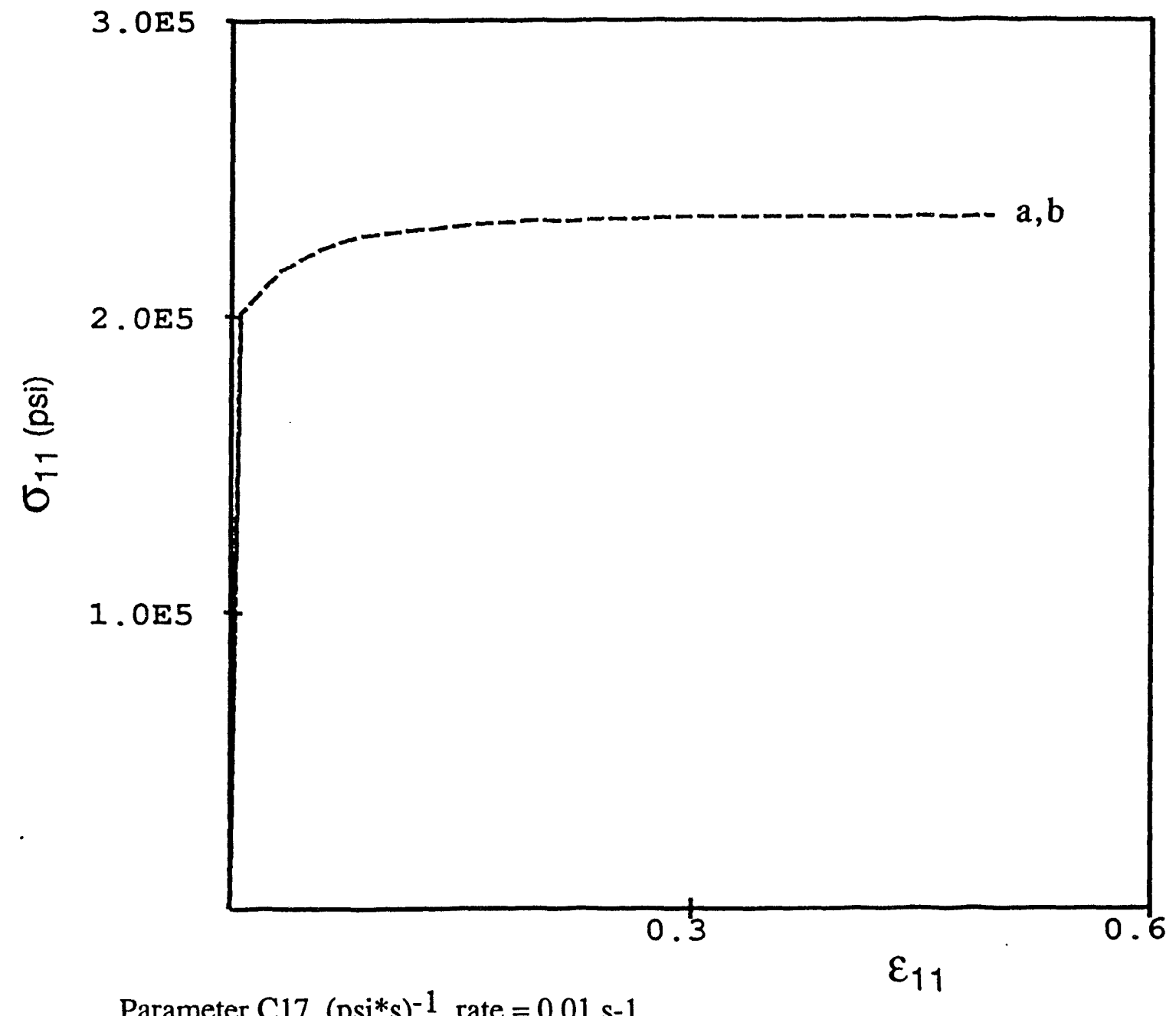

Parameter C17 $\left(\mathrm{psi}^{*} \mathrm{~s}\right)^{-1}$, rate $=0.01 \mathrm{~s}-1$

a $4.77 \mathrm{e}-07$.

b $4.29 \mathrm{e}-06$. 
UNLIMITED RELEASE

\section{INITIAL DISTRIBUTION}

U. S. Department of Energy

Attn: G. A. Sanders

DP-20.1

Washington, DC 20545

0829 K. V. Diegert, 12323

0490 V. J. Johnson, 12324

0465 J. F. Ney, 05003

0490 S. D. Spray, 12331

0492 R. D. Pederson, 12332

0492 D. A. Summers, 12332

0191 R. E. Smith, 12333

0443 H. S. Morgan, 01561

0443 G. W. Wellman, 01561

0443 J. D. Gruda, 01561

0340 R. J. Salzbrenner, 01832 (5)

0630 J. F. Jones, Jr., 02800

0501 P. J. Wilson, 02562

0311 T. J. Williams, 02571

0328 M. J. DeSpain, 02574

0328 J. A. Wilder, 02574

0641 R. S. Urenda, 02643

0641 W. R. Leuenberger, 02645

0641 S. F. Kuehn, 02542

0481 L. B. Traylor, 05167

9001 J. C. Crawford, 8000

Attn: D. L. Crawford, 1900, MS 9003

E. E. Ives, 5200, MS 9006

J. B. Wright, 5300, MS 9005

M. E. John, 8100, MS 9004

R. J. Detry, 8200, MS 9037

W. J. McLean, 8300 , MS 9054

L. A. Hiles, 8400, MS 9015

P. E. Brewer, 8500, MS 9002

L. A. West, 8600, MS 9901

R. C. Wayne, 8700 , MS 9401

9015 C. T. Oien, 5375

9015 J. L. Cherry, 5375

9042 M. L. Chiesa, 8741

9042 L. E. Voelker, 8741

9042 P. E. Nielan, 8742

9042 J. J. Dike, 8742

9042 K. V. Trinh, 8742 (15)

9043 M. L. Callabresi, 8743

9043 D. J. Bammaın, 8743
9043 M. F. Horstemeyer, 8743

9043 V. Prantil, 8743

9044 W. A. Kawwahara, 8746

9053 C. M. Hartwig, 8366

9021 Publications for OSTI, 8535 (10)

9281 Publications /Technical Library

Processes, 7141

0899 Technical Library Processes

Division, 7141 (3)

9018 Central Technical Files, 8523-2 (3) 

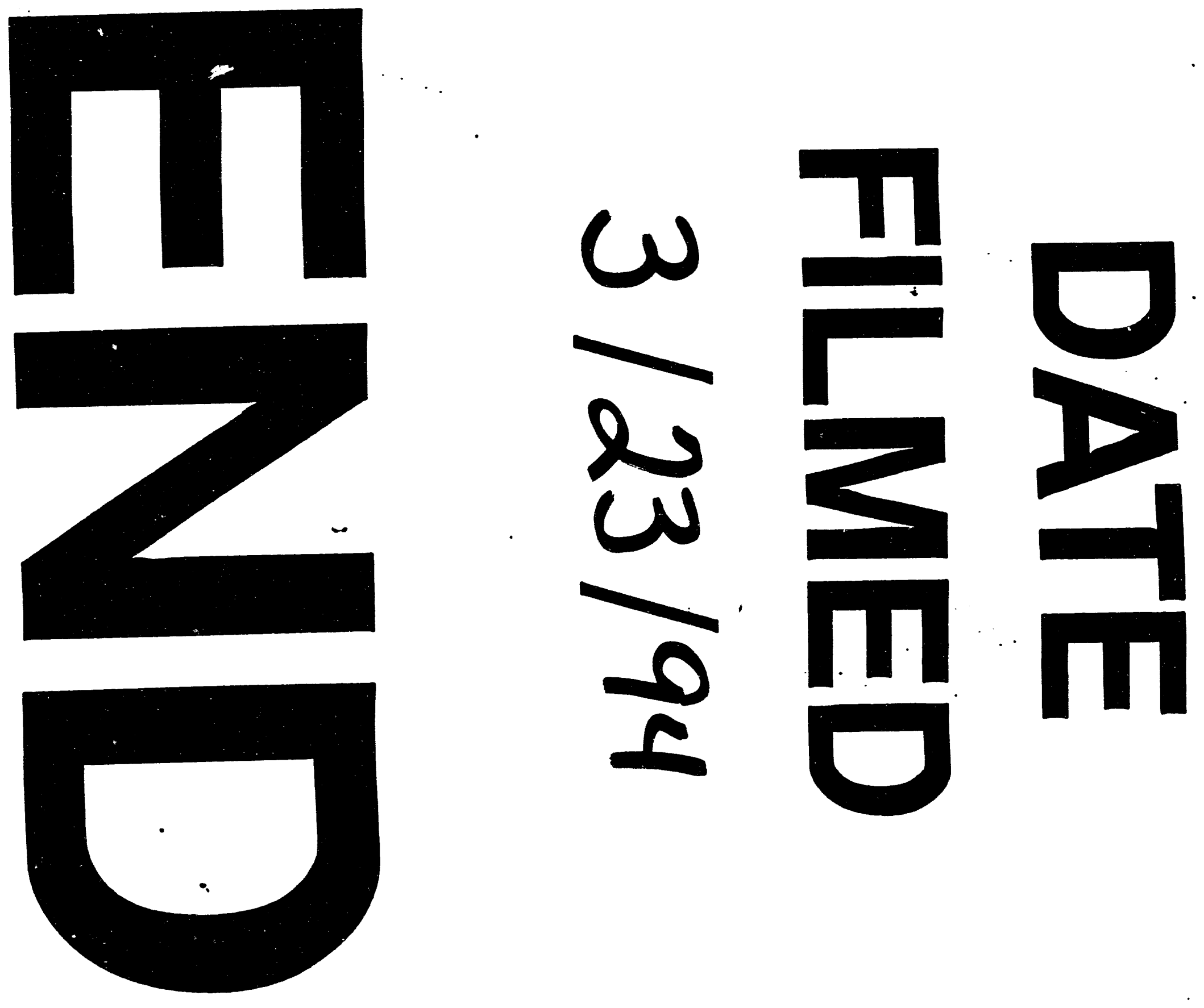
